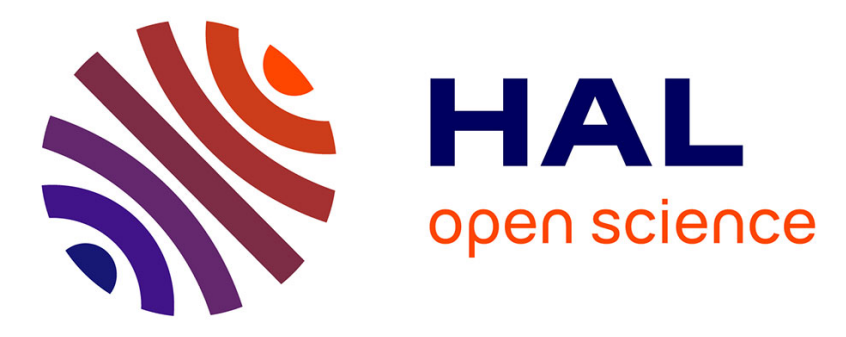

\title{
Structure, chemical bonding, and 45Sc solid state NMR of Sc2RuSi2
}

\author{
Thomas Harmening, Adel F. Al Alam, Samir F. Matar, Helmut Eckert, \\ Rainer Pöttgen
}

\section{- To cite this version:}

Thomas Harmening, Adel F. Al Alam, Samir F. Matar, Helmut Eckert, Rainer Pöttgen. Structure, chemical bonding, and 45Sc solid state NMR of Sc2RuSi2. Solid State Sciences, 2009, 11 (7), pp.12391245. 10.1016/j.solidstatesciences.2009.03.015 . hal-00399600

\section{HAL Id: hal-00399600 https://hal.science/hal-00399600}

Submitted on 22 Sep 2009

HAL is a multi-disciplinary open access archive for the deposit and dissemination of scientific research documents, whether they are published or not. The documents may come from teaching and research institutions in France or abroad, or from public or private research centers.
L'archive ouverte pluridisciplinaire HAL, est destinée au dépôt et à la diffusion de documents scientifiques de niveau recherche, publiés ou non, émanant des établissements d'enseignement et de recherche français ou étrangers, des laboratoires publics ou privés. 


\title{
Structure, Chemical Bonding, and ${ }^{45} \mathrm{Sc}$ Solid State NMR of $\mathrm{Sc}_{2} \mathrm{RuSi}_{2}$
}

\author{
Thomas Harmening ${ }^{\mathrm{a}}$, Adel Al Alam ${ }^{\mathrm{b}}$, Samir F. Matar ${ }^{\mathrm{b}}$, Hellmut Eckert ${ }^{\mathrm{c}}$, \\ Rainer Pöttgen ${ }^{\mathrm{a}, *}$
}

a Institut für Anorganische und Analytische Chemie and NRW Graduate School of Chemistry, Universität Münster, Corrensstrasse 30, D-48149 Münster, Germany E-mail:pottgen@uni-muenster.de

b Université de Bordeaux, CNRS, ICMCB, 87 Avenue du Docteur Albert Schweitzer, 33608 Pessac Cedex, France

E-mail:matar@icmcb-bordeaux.cnrs.fr

c Institut für Physikalische Chemie and NRW Graduate School of Chemistry, Universität Münster, Corrensstrasse 30, D-48149 Münster, Germany

E-mail:eckerth@uni-muenster.de

\section{A R T I C L E IN F O}

Article history:

Received

Accepted

Available online \#\#\#\#

Keywords:

Intermetallic compounds

Crystal chemistry

$\mathrm{Sc}_{2} \mathrm{RuSi}_{2}$

Solid State NMR

Electronic structure

\section{A B S T R A C T}

The silicide $\mathrm{Sc}_{2} \mathrm{RuSi}_{2}$ was synthesized from the elements by arc-melting. The structure was refined on the basis of single crystal X-ray diffractometer data: $\mathrm{Sc}_{2} \mathrm{CoSi}_{2}$ type, 
$C 2 / m, a=1004.7(2), b=406.8(1), c=946.6(2) \mathrm{pm}, \beta=117.95(2)^{\circ}, \mathrm{w} R 2=0.0230,743$ $\mathrm{F}^{2}$ values, and 32 variables. The structure consists of a rigid three-dimensional [ $\left.\mathrm{RuSi}_{2}\right]$ network in which the two crystallographically independent scandium atoms fill larger cages of coordination numbers 16 and 15, respectively. The [RuSi ${ }_{2}$ ] network shows short $\mathrm{Ru}-\mathrm{Si}$ distances (234-247 pm) and two different $\mathrm{Si}_{2}$ pairs: Sil-Sil at 247 and $\mathrm{Si} 2-\mathrm{Si} 2$ at $243 \mathrm{pm}$. Each silicon atom has trigonal prismatic $\mathrm{Sc}_{6}$ (for $\mathrm{Si}$ ) or $\mathrm{Sc}_{4} \mathrm{Ru}_{2}$ (for Si1) coordination. These building units are condensed via common edges and faces. The various Sc-Sc distances between the prisms range from 327 to $361 \mathrm{pm}$. From electronic structure investigation within DFT, chemical bonding shows a major role of $\mathrm{Ru}-\mathrm{Si}$ bonding and the presence of strong electron localization around $\mathrm{Si}-\mathrm{Si}$ pairs pointing to a polyanionic silicide network $\left[\mathrm{RuSi}_{2}\right]^{\delta-}$. The ${ }^{45} \mathrm{Sc}$ MAS NMR spectra recorded at 11.7 and 9.4 $\mathrm{T}$ clearly resolve the two distinct scandium sites. The large electric field gradients present at both scandium sites result in typical lineshapes arising from second order quadrupole perturbation effects.

(C) 2008 Elsevier Masson SAS. All rights reserved.

* Correspondence and reprints: Institut für Anorganische und Analytische Chemie, Westfälische Wilhelms-Universität Münster, Corrensstrasse 30, 48149 Münster, Germany, Tel.: +49-251-83-36001; Fax: +49-251-83-36002

E-mail address: pottgen@uni-muenster.de (R. Pöttgen)

\section{Introduction}

The Sc $-T-X$ systems with $T=$ late transition metal and $X=$ element of the $3^{\text {rd }}, 4^{\text {th }}$, or $5^{\text {th }}$ main group have intensively been studied with respect to phase analyses. The basic information on the phase diagrams and crystallographic data have been reviewed by Kotur and Gratz [1]. Due to the small size of scandium [2, 3], as compared to the series of rare earth metals, the $\mathrm{Sc}_{\mathrm{x}} T_{\mathrm{y}} X_{\mathrm{z}}$ compounds behave in an ambivalent way. Either they crystallize with the same structure as the compounds with the late rare earth $(R E)$ metals or they adopt their own structure type. Recent examples for this behavior are ScAuGe $[4,5]$ and ScAuSi $[6,7]$. While ScAuGe is isotypic with the REAuGe germanides, ScAuSi adopts its own structure type with a peculiar stacking sequence of the $\mathrm{Au}_{3} \mathrm{Si}_{3}$ networks. 
We have recently started a systematic investigation of such intermetallic scandium compounds with respect to their crystal chemical features and their ${ }^{45} \mathrm{Sc}$ solid state NMR characteristics. NMR has proven to be a very sensitive tool for revealing detailed local structural information, revealing superstructure formation in $\mathrm{ScAgSn}$ [8] and characterizing various defects and their distributions in the non-stoichiometric materials $\mathrm{ScNi}_{2-\mathrm{x}} \mathrm{Sn}$ [9] and $\mathrm{ScNi}_{1-\mathrm{x}} \mathrm{Si}_{3}$ [10]. These studies have been extended to the equiatomic stannides ScTSn [11] and ScTSi silicides [12]. During attempts to synthesize ScRuSi with the ZrNiAl type structure [12, 13], we observed an orthorhombic, TiNiSi type high-temperature phase of this equiatomic silicide and hints for a silicide of composition $\mathrm{Sc}_{2} \mathrm{RuSi}_{2}$. The synthesis of this silicide and a detailed characterization of chemical

bonding and the ${ }^{45} \mathrm{Sc}$ solid state NMR data are reported herein. This phase is most likely similar to the previously reported compound with the tentative composition ' $\mathrm{Sc}_{3} \mathrm{Ru}_{2} \mathrm{Si}_{6}$ ' [14].

\section{Experimental}

\subsection{Syntheses}

Starting materials for the preparation of $\mathrm{Sc}_{2} \mathrm{RuSi}_{2}$ were a scandium ingot (Johnson Matthey), ruthenium powder (Degussa-Hüls, ca. 200 mesh), and silicon lumps (Wacker), all with stated purities better than $99.9 \%$. In the first step, pieces of the scandium ingot were arc-melted [15] under argon (ca. 600 mbar) to a small button. The argon was purified before with titanium sponge $(870 \mathrm{~K})$, silica gel and molecular sieves. The scandium button was then mixed with a cold-pressed pellet $(6 \mathrm{~mm} \varnothing)$ of ruthenium and pieces of the silicon lumps in the ideal 2:1:2 atomic ratio and arc-melted. The product button was re-melted three times to ensure homogeneity ( $<0.5 \%$ weight loss). The polycrystalline $\mathrm{Sc}_{2} \mathrm{RuSi}_{2}$ sample is light grey and stable in air for weeks. Small single crystals exhibit metallic lustre.

\subsection{EDX analyses}

The single crystal investigated on the diffractometer was studied by energy dispersive analyses of X-rays (EDX) using a Leica 420i scanning electron microscope with $\mathrm{Sc}, \mathrm{Ru}$, and $\mathrm{SiO}_{2}$ as standards. The crystal (mounted on a quartz fibre) was first coated with a thin carbon film to ensure conductivity. The semi-quantitative analyses (39 \pm 2 at.- 
$\% \mathrm{Sc}: 20 \pm 2$ at.- $\% \mathrm{Ru}: 41 \pm 2$ at.- $\% \mathrm{Si}$ ) was in good agreement with the ideal composition. No impurity elements heavier than sodium (detection limit of the instrument) have been detected.

\subsection{X-ray powder diffraction}

The $\mathrm{Sc}_{2} \mathrm{RuSi}_{2}$ sample was characterized through a Guinier powder pattern $\left(\mathrm{Cu} \mathrm{K} \alpha_{1}\right.$ radiation, $\alpha$-quartz: $a=491.30, c=540.46 \mathrm{pm}$ as internal standard). The Guinier camera was equipped with an imaging plate technique (Fujifilm, BAS-READER 1800). The monoclinic lattice parameters (Table 1) were obtained through a least-squares routine. The correct indexing was ensured through comparison of the experimental pattern with a calculated one [16].

\subsection{Single crystal X-ray data}

Small irregularly shaped single crystals of $\mathrm{Sc}_{2} \mathrm{RuSi}_{2}$ were isolated from the crushed arc-melted sample and investigated on a Buerger precession camera (white Mo radiation, Fujifilm imaging plate) in order to check the quality for intensity data collection. The data set was collected at room temperature by use of an IPDS II diffractometer (graphite monochromatized Mo K $\alpha$ radiation; oscillation mode). A numerical absorption correction was applied to the data set. Details on the crystallographic data are given in Table 1.

\subsection{Solid State NMR}

${ }^{45}$ Sc magic-angle spinning (MAS) NMR spectra were recorded at ambient temperature at resonance frequencies of 121.5 and $97.2 \mathrm{MHz}$ on a Bruker DSX-500 and a Bruker DSX-400 spectrometer, respectively, using a $2.5 \mathrm{~mm}$ MAS NMR probe operated at a rotation frequency of $25 \mathrm{kHz}$. To minimize undesirable effects of probe detuning and sample heating of the highly metallic sample, the finely ground powder was mixed with silica in a 1:1 mass ratio in the MAS experiment. Acquisition parameters were a $0.2 \mu \mathrm{s}$ $\left(22.5^{\circ}\right.$ solid flip angle) pulse length and a recycle delay of $0.5 \mathrm{~s}$. The ${ }^{45} \mathrm{Sc}$ NMR resonance shifts are referenced to $0.2 \mathrm{M}$ scandium nitrate aqueous solution. Attempts of recording ${ }^{29} \mathrm{Si}$ MAS-NMR spectra were unsuccessful. In analogy to similar experiences made with the compound $\mathrm{ScNiSi}_{3}$ [10] we suspect that the ${ }^{29} \mathrm{Si}$ resonance is broadened beyond detectability by electronic disordering effects in the structure, causing a wide distribution of resonance shifts. 


\subsection{Electronic Structure Calculations}

The electronic structure calculations were performed using the augmented spherical wave (ASW) method $[17,18]$ built within the density functional theory DFT framework $[19,20]$. All valence states were treated as band states. In the minimal ASW basis set, the outermost shells were chosen to represent the valence states using partial waves up to $l_{\max }+1=3$ for $\mathrm{Sc}, \mathrm{Ru}$ and $\mathrm{Si}$. The completeness of the valence basis set was checked for charge convergence, i.e. less than 0.1 electrons for $l_{\max }+1$. The self-consistent field calculations were run to a convergence of $10^{-8}$ for the charge density and the accuracy of the method is in the range of about $10^{-8}$ Ryd. regarding energy differences. The effects of exchange and correlation were treated based on the local density approximation LDA [21].

To extract more information about the nature of the interactions between the atomic constituents from electronic structure calculations, the covalent bond energy criterion ECOV [22] was used. This approach combines both the crystal orbital Hamilton population (COHP [23]) and crystal orbital overlap population (COOP [24]) to calculate quantities independent of the particular choice of the potential zero. In the plots, negative, positive and zero magnitudes of ECOV are indicative of bonding, antibonding, and nonbonding interactions, respectively.

\section{Results and Discussion}

\subsection{Structure Refinement}

Analyses of the diffractometer data set revealed a $C$-centered monoclinic lattice and no further systematic extinctions, leading to space groups $C 2, C m$, and $C 2 / m$, of which the centrosymmetric group was found to be correct during structure refinement. The starting atomic parameters were deduced from an automatic interpretation of direct methods with SHELXS-97 [25] and the structure was refined using SHELXL-97 (fullmatrix least-squares on $F^{2}$ ) [26] with anisotropic atomic displacement parameters for all atoms. The refinement readily revealed isotypism with $\mathrm{Zr}_{2} \mathrm{CoSi}_{2}$ [27] and we then used the setting for isotypic $\mathrm{Yb}_{2} \mathrm{IrGe}_{2}$ [28] for the final refinement cycles. Refinement of the occupancy parameters showed full occupancy within two standard deviations. The final 
difference electron-density synthesis was flat. The results of the structure refinement are summarized in Table 1. The atomic coordinates and the interatomic distances are listed in Tables 2 and 3. Further information on the structure refinement is available.*

* Details may be obtained from: Fachinformationszentrum Karlsruhe, D-76344 Eggenstein-Leopoldshafen (Germany), by quoting the Registry No. CSD-420133.

\subsection{Crystal Chemistry}

Monoclinic $\mathrm{Sc}_{2} \mathrm{RuSi}_{2}$ reported herein is obviously identical with the previously reported compound with the tentative composition ' $\mathrm{Sc}_{3} \mathrm{Ru}_{2} \mathrm{Si}_{6}$ ' [14]. In the contribution by Braun and Segre, the powder patterns of the ' $\mathrm{Sc}_{3} \mathrm{Ru}_{2} \mathrm{Si}_{6}$ ' sample was indexed on the basis of an orthorhombic unit cell with cell parameters $a=893.9(8), b=906.1(8), c=$ $417.5(7) \mathrm{pm}$. The cell volume of $V=0.3382 \mathrm{~nm}^{3}$ is close to the value of $0.3418 \mathrm{~nm}^{3} \mathrm{ob}-$ tained during the present study.

The $\mathrm{Sc}_{2} \mathrm{RuSi}_{2}$ structure contains two scandium, one ruthenium, and two silicon sites. As emphasized in Figure 1, from a geometrical point of view, each of the silicon atoms has trigonal prismatic coordination, i.e. Si1 by $4 \mathrm{Sc}+2 \mathrm{Ru}$ and $\mathrm{Si} 2$ by $6 \mathrm{Sc}$ atoms. All rectangular faces of these prisms are capped by further scandium, ruthenium, or silicon atoms, leading to coordination number 9 as frequently observed in related intermetallic compounds $[13,29,30]$. The trigonal prisms are condensed via common edges and faces forming two-dimensional building blocks which extend in the $b c$ plane. Due to the $C$ centering, every other building block is shifted by half the translation period $b$.

Together, the ruthenium and silicon atoms build up a three-dimensional network of condensed $\mathrm{RuSi}_{4 / 2}$ tetrahedra (Figures 2 and 3) which are further connected via $\mathrm{Si}-\mathrm{Si}$ bonds. The Ru-Si distances range from 234 to $247 \mathrm{pm}$, all smaller than the sum of the covalent radii of $251 \mathrm{pm} \mathrm{[2],} \mathrm{already} \mathrm{indicating} \mathrm{substantial} \mathrm{Ru}-\mathrm{Si}$ bonding. The ruthenium atoms in the centres of the tetrahedra are separated by $307 \mathrm{pm}$, much longer than the average $\mathrm{Ru}-\mathrm{Ru}$ distance of $268 \mathrm{pm}$ in $h c p$ ruthenium [3]. The $\mathrm{Si}-\mathrm{Si}$ distances between the rows of condensed $\mathrm{RuSi}_{4 / 2}$ tetrahedra are $247 \mathrm{pm}$ for Si1-Sil and $243 \mathrm{pm}$ for Si2-Si2, slightly longer than in elemental silicon (235 pm) [3]. Besides the strong Ru$\mathrm{Si}$ bonds, also the Si1-Si1 and $\mathrm{Si} 2-\mathrm{Si} 2$ bonding significantly contributes to the stability of the three-dimensional $\left[\mathrm{RuSi}_{2}\right]$ network. 
Both crystallographically independent scandium sites have high coordination numbers, i.e. $\mathrm{CN} 16(5 \mathrm{Sc}+4 \mathrm{Ru}+7 \mathrm{Si})$ for $\mathrm{Sc} 1$ and $\mathrm{CN} 15(7 \mathrm{Sc}+2 \mathrm{Ru}+6 \mathrm{Si})$ for $\mathrm{Sc} 2$. The various Sc-Si (276-330 pm) and Sc-Ru (291-307 pm) distances are all longer than the sums of the covalent radii [2] of $261(\mathrm{Sc}+\mathrm{Si})$ and $278(\mathrm{Sc}+\mathrm{Ru})$, respectively. We can therefore assume weaker bonding interactions between these atoms. In contrast, a variety of relatively short Sc-Sc distances (327-361 pm) occurs within and between the trigonal prismatic units presented in Fig. 1. The shorter ones compare well with $h c p$ scandium $(6 \times 325$ and $6 \times 331 \mathrm{pm})[3]$.

\subsection{Electronic Structure and Chemical Bonding Analyses}

In Fig. 4 showing the site-projected density of states (PDOS) for $\mathrm{Sc}_{2} \mathrm{RuSi}_{2}$ the Fermi level $\left(\mathrm{E}_{\mathrm{F}}\right)$ is taken as zero energy. This is also followed in the two following plots describing the chemical bonding. The system is metallic because $\mathrm{E}_{\mathrm{F}}$ is crossed by $\mathrm{Si}(\mathrm{sp})$ and d-like states arising both from the lower part of the Sc and the upper part of the Ru band. The two transition metal PDOS are mainly dominated by the $\mathrm{d}$ states. The filling of the respective $d$ sub-shells in the metals explains the PDOS shapes, so that Sc $4 \mathrm{~d}$ states are centered above $\mathrm{E}_{\mathrm{F}}$ around $3 \mathrm{eV}$ within the conduction band $(\mathrm{CB})$ and $\mathrm{Ru} 4 \mathrm{~d}$ are found centered at $-3 \mathrm{eV}$ within the VB. The lower part of the valence band (VB) between -11 and $-6 \mathrm{eV}$ shows a differentiation of Si s like states; the Sil lying at lower energy than Si2. This is indicative of a different chemical behavior exhibited by them, meaning that Sil should be stabilized further by its bonding within the structure. This is quantified from the distances between $\mathrm{Ru}$ and $\mathrm{Si}$, whereby $\mathrm{d}(\mathrm{Ru}-\mathrm{Si} 1)=234.1 \mathrm{pm}$ while $\mathrm{d}(\mathrm{Ru}-\mathrm{Si} 2)=247.1 \mathrm{pm}$. The consequence of this feature and that of another original one pertaining to the $\mathrm{Si}-\mathrm{Si}$ distance -which is the smallest for the Si2 substructure- are better explained below while discussing the chemical bonding in terms of the covalent bond energy ECOV criterion and the electron localization function (ELF).

The results for the covalent bond energies ECOV, accounting for all atoms from each kind, are presented in Fig. 5 (top and bottom), respectively, detailing Sc and Ru interactions with $\mathrm{Si}$ on one hand and the $\mathrm{Si}-\mathrm{Si}$ bonding on the other hand.

The bonding between $\mathrm{Sc}$ and $\mathrm{Ru}$ on one hand and $\mathrm{Si}$ on the other hand shows in Fig. 5 (top), a clearly dominant $\mathrm{Ru}-\mathrm{Si} 1$ bonding interaction within the VB occurs due to the mixing between $\mathrm{Ru}-\mathrm{d}$ and $\mathrm{Si}$-sp states in the energy window ranging from -6 up to -2 
$\mathrm{eV}$. This is explained by the small $\mathrm{Ru}-\mathrm{Sil}$ distance given above, i.e. with respect to the other interatomic distances. The bonding $\mathrm{Ru}-\mathrm{Si} 2$ interaction follows $\mathrm{Ru}-\mathrm{Si} 1$ as the second most dominant, then to a lesser extent Sc-Si bonds. The major part of the VB is bonding with small intensity antibonding interactions arising from $\mathrm{Ru}-\mathrm{Si}$ bonds just below $\mathrm{E}_{\mathrm{F}}$. Thus the system is stabilized by the large bonding arising from Ru-Sil within the VB.

The other feature which deserves attention is the bonding within the two Si substructures sketched in Fig. 5 (bottom). Although the ECOV intensities are much smaller ( 20 times) with respect to Fig. 5 (top), interesting features appears relative to the interaction between the different $\mathrm{Si}$ substructures. There is evidence of a non negligible Si1-Sil bonding mainly in the -6 to $-3 \mathrm{eV}$ range with a larger intensity than the Si2-Si2 bonding. The interaction between $\mathrm{Si} 1$ and $\mathrm{Si} 2$ is of much smaller intensity. This is not concomitant with the respective $\mathrm{Si}-\mathrm{Si}$ separations, i.e. the smallest distance being d(Si2$\mathrm{Si} 2)=243 \mathrm{pm}$. An explanation of this behavior can be found in the coordination polyhedron of the silicon atoms. It is shown in subsection 3.2 that Sil is surrounded by $4 \mathrm{Sc}$ and $2 \mathrm{Ru}$ while $\mathrm{Si} 2$ lies in an environment of $6 \mathrm{Sc}$ atoms. Further, one can establish from an inspection of Table 3 that Sc2 is dominant with respect to Sc1 in the neighborhood of Si2. This suggests a shielding practiced by Sc2 within the field between 2 Si2 atoms, reducing the overlap between both $\mathrm{Si} 2$ orbitals and subsequently their binding.

A further assessment of this behavior can be found within the mapping of the electron localization function ELF, which is a direct space analysis of the electron density introduced by Becke and Edgecomb [31]. The unit-less ELF function is normalized between 0 and 1 for zero and full localization with blue and red color, respectively. At 1/2, the ELF function corresponds to a free electron like behavior (with green contours). Fig. 6 shows an ac plane crossing all 3 chemical species within the $\mathrm{Sc}_{2} \mathrm{RuSi}_{2}$ structure which is shown here in the primitive monoclinic mode of the unit cell. The ELF projections are shown at $y=0$ and $y=1 / 2$, respectively. There can be observed a departure of electrons from Sc whose ELF contours become blue while $\mathrm{Ru}$ sites are surrounded with green contours pointing to free electron like behavior. On the contrary a strong localization is observed around the Si sites, which are arranged pairwise as depicted in Fig. 1. From this the silicide labeling of $\mathrm{Sc}_{2} \mathrm{RuSi}_{2}$ is confirmed together with the remarkable feature of Si-Si pairs. 


\section{4. ${ }^{45}$ Sc Solid state NMR Spectroscopy}

Fig. 7 shows the ${ }^{45} \mathrm{Sc}$ MAS NMR spectrum of $\mathrm{Sc}_{2} \mathrm{RuSi}_{2}$ at 11.7 and $9.4 \mathrm{~T}$, respectively. The structural difference in the local environment between Sc1 and Sc2 is clearly resolved by a $136 \mathrm{ppm}$ resonance shift difference in the spectrum. Due to the low monoclinic scandium site symmetry $(m)$ the MAS NMR line shapes are visibly affected by second-order quadrupolar perturbations. The effect of the second-order perturbation of the central $|1 / 2\rangle\langle->|-1 / 2>$ transition energy is increasing with decreasing field strength. Therefore the structure of the line shapes is more pronounced in the low field spectrum. Table 4 summarizes the values of the nuclear electric quadrupolar coupling constants, $\mathrm{C}_{\mathrm{Q}}=\mathrm{eQV}_{\mathrm{zz}} / \mathrm{h}$, and the asymmetry parameters $\eta_{\mathrm{Q}}=\left(\mathrm{V}_{\mathrm{xx}}-\mathrm{V}_{\mathrm{yy}}\right) / \mathrm{V}_{\mathrm{zz}}$, extracted from the spectrum using the DMFIT simulation routine [32]. In the above definitions, $Q$ $=0.22 \times 10^{-28} \mathrm{~m}^{2}$ is the ${ }^{45} \mathrm{Sc}$ nuclear electric quadrupole moment, and $\mathrm{V}_{\mathrm{xx}}, \mathrm{V}_{\mathrm{yy}}$, and $\mathrm{V}_{\mathrm{zz}}$ are the principal components of the electric field gradient tensor at the scandium site. A small amount of impurity is creating a shoulder at the low-field side of the signal at $1113 \mathrm{ppm}$. This was incorporated by a simple Gaussian line shape located at $1125 \mathrm{ppm}$, having about $6 \%$ of the overall intensity. Unfortunately, the nuclear electric quadrupole parameters and also the chemical shifts of the two scandium sites are too close to each other to permit a reliable signal assignment based on theoretical calculations. Furthermore, based on Table 3 the magnetic dipole-dipole coupling strengths to nearby ${ }^{29} \mathrm{Si}$ nuclei are predicted to be nearly identical for both scandium sites, hence forestalling a site assignment based on ${ }^{45} \mathrm{Sc}\left\{{ }^{29} \mathrm{Si}\right\}$ double resonance experiments as previously demonstrated for ScAuSi [7].

\section{Acknowledgments}

We thank Dipl.-Ing. U. Ch. Rodewald and Dr. R.-D. Hoffmann for the single crystal data collection. This work was financially supported by the Deutsche Forschungsgemeinschaft within the priority program Lanthanoidspezifische Funktionaliäten in Molekül und Material. T.H. is indebted to the NRW Graduate School of Chemistry for a PhD stipend. We acknowledge computational facilities provided by the University Bordeaux 1 within the M3PEC Mésocentre Régional (http://www.m3pec.u-bordeaux1.fr) supercomputers. 


\section{References}

[1] B. Ya. Kotur, E. Gratz, Scandium Alloy Systems and Intermetallics, in: K. A. Gschneidner Jr., L. Eyring (eds.), Handbook on the Physics and Chemistry of Rare Earths, Elsevier, Amsterdam, Volume 27, Chapter 175 (pp. 339-533) (1999).

[2] J. Emsley, The Elements, Clarendon Press, Oxford (1989).

[3] J. Donohue, The Structures of the Elements, Wiley, New York (1974).

[4] D. Rossi, R. Marazza, R. Ferro, J. Alloys Compd. 187 (1992) 267.

[5] R. Pöttgen, H. Borrmann, C. Felser, O. Jepsen, R. Henn, R. K. Kremer, A. Simon, J. Alloys Compd. 235 (1996) 170.

[6] M. L. Fornasini, A. Iandelli, M. Pani, J. Alloys Compd. 187 (1992) 243.

[7] C. P. Sebastian, L. Zhang, H. Eckert, R. Pöttgen, Z. Naturforsch. 62b (2007) 173.

[8] C. P. Sebastian, L. Zhang, C. Fehse, R.-D. Hoffmann, H. Eckert, R. Pöttgen, Inorg. Chem. 46 (2007) 771.

[9] C. P. Sebastian, H. Eckert, R. Pöttgen, Solid State Sci. 9 (2007) 357.

[10] Th. Harmening, H. Eckert, D. Johrendt, R. Pöttgen, Solid State Sci.10 (2008) 544.

[11] T. Harmening, C. P. Sebastian, L. Zhang, C. Fehse, H. Eckert, R. Pöttgen, Solid State Sci. 10 (2008) 1395.

[12] T. Harmening, H. Eckert, R. Pöttgen, unpublished results.

[13] E. Hovestreydt, N. Engel, K. Klepp, B. Chabot, E. Parthé, J. Less-Common Met. 85 (1982) 247.

[14] H. F. Braun, C. U. Segre, Solid State Commun. 35 (1980) 735.

[15] R. Pöttgen, Th. Gulden, A. Simon, GIT Labor-Fachzeitschrift 43 (1999) 133.

[16] K. Yvon, W. Jeitschko, E. Parthé, J. Appl. Crystallogr. 10 (1977) 73.

[17] A. R. Williams, J. Kübler, C. D. Gelatt, Jr., Phys. Rev. B 19 (1979) 6094.

[18] V. Eyert, The Augmented Spherical Wave Method - A Comprehensive Treatment, Lect. Notes Phys. 719, Springer, Berlin Heidelberg (2007).

[19] P. Hohenberg, W. Kohn, Phys. Rev. 136 (1964) B864.

[20] W. Kohn, L. J. Sham, Phys. Rev. 140 (1965) A1133.

[21] S. H. Vosko, L. Wilk, M. Nusair, Can. J. Phys. 58 (1980) 1200.

[22] G. Bester, M. Fähnle, J. Phys.: Condens. Matter 13 (2001) 11541.

[23] R. Dronskowski, P. E. Blöchl, J. Phys. Chem. 97 (1993) 8617. 
[24] R. Hoffmann, Angew. Chem. Int. Ed. Engl. 26 (1987) 846.

[25] G. M. Sheldrick, SHELXL-97, Program for Crystal Structure Refinement, University of Göttingen, Germany, 1997.

[26] G. M. Sheldrick, SHELXS-97, Program for the Solution of Crystal Structures, University of Göttingen, Germany, 1997.

[27] Ya. P. Yarmolyuk, L. A. Lysenko, Dopov. Akad Nauk Ukr. RSR A 40 (1978) 376.

[28] U. Ch. Rodewald, R. Pöttgen, Solid State Sci. 5 (2003) 487.

[29] E. Parthé, B. Chabot, Crystal Structures and Crystal Chemistry of Ternary Rare Earth-Transition Metal Borides, Silicides and Homologues, in: K. A. Gschneidner Jr., L. Eyring (eds.), Handbook on the Physics and Chemistry of Rare Earths, Elsevier, Amsterdam, Volume 6, Chapter 48 (pp. 113-334) (1984).

[30] E. Parthé, L. Gelato, B. Chabot, M. Penzo, K. Cenzual, R. Gladyshevskii, TYPIX-Standardized Data and Crystal Chemical Characterization of Inorganic Structure Types. Gmelin Handbook of Inorganic and Organometallic Chemistry, $8^{\text {th }}$ edition, Springer, Berlin (1993).

[31] A. D. Becke, K. E. Edgecomb, J. Chem. Phys. 92 (1990) 5397.

[32] D. Massiot, F. Fayon, M. Capron, I. King, S. Le Calve, B. Alonso, J. O. Durand, B. Bujoli, Z. Gan, G. Hoatson, Magn. Reson. Chem. 40 (2002) 70. 
Table 1

Crystallographic data and structure refinement of $\mathrm{Sc}_{2} \mathrm{RuSi}_{2}$.

\begin{tabular}{ll}
\hline Formula & $\mathrm{Sc}_{2} \mathrm{RuSi}_{2}$ \\
Structure type & $\mathrm{Zr}_{2} \mathrm{CoSi}_{2}$ \\
Space group & $C 2 / m$ \\
Formula units per cell / Z & 4 \\
Lattice parameters & $a=1004.7(2)$ \\
(Guinier powder data) & $b=406.8(1)$ \\
& $c=946.6(2)$ \\
& $\beta=117.95(2)$ \\
& $V=0.3418 \mathrm{~nm}^{3}$ \\
Molar mass [g mol ${ }^{-1}$ ] & 247.17 \\
Crystal size [ $\mu \mathrm{m}^{3}$ ] & $10 \times 20 \times 40$ \\
$\omega$ range; increment & $0-180^{\circ} ; 1.0^{\circ}$ \\
Exposure time & $9 \mathrm{~min}$ \\
Integr. param. A, B, EMS & $14.0 ; 2.8 ; 0.021$ \\
Calculated density [g cm & 4.80 \\
Transmission (max $\left./ \mathrm{min}^{-3}\right)$ & 1.25 \\
Radiation & $\mathrm{Mo} \mathrm{K}_{\alpha}(\lambda=71.073 \mathrm{pm})$ \\
Absorption coeffient, $\mu\left[\mathrm{mm}^{-1}\right]$ & 8.6 \\
F(000) & 456 \\
$\theta$-range [ $\left.{ }^{\circ}\right]$ & $4-34$ \\
Range in $h k l$ & $\pm 15, \pm 6, \pm 14$ \\
Total reflections & 2463 \\
Independent reflections & $743\left(\mathrm{R}_{\text {int }}=0.0305\right)$ \\
Reflections with $I \geq 2 \sigma(I)$ & $592\left(\mathrm{R}_{\text {sigma }}=0.0379\right)$ \\
Data / parameters & $743 / 32$ \\
Goodness-of-fit & 0.893 \\
$R$ indices $[I \geq 2 \sigma(\mathrm{I})]$ & $R 1=0.0193$ \\
& $w R 2=0.0214$ \\
$R$ indices (all data) & $R 1=0.0374$ \\
& $w R 2=0.0230$ \\
Extinction coefficient & $0.00364(16)$ \\
Largest diff. peak and hole [e / $\AA^{3}$ ] & 0.84 and -0.92 \\
\hline
\end{tabular}


Table 2

Atomic coordinates and anisotropic displacement parameters $\left(\mathrm{pm}^{2}\right)$ for $\mathrm{Sc}_{2} \mathrm{RuSi}_{2}$. The anisotropic displacement factor exponent takes the form: $-2 \pi^{2}\left[\left(h a^{*}\right)^{2} U_{11}+\ldots+2 h k a^{*} b^{*} U_{12}\right] . \mathrm{U}_{\mathrm{eq}}$ is defined as one third of the trace of the orthogonalized $\mathrm{U}_{\mathrm{ij}}$ tensor. $U_{12}=U_{23}=0$.

\begin{tabular}{lccccccccc}
\hline Atom & $\begin{array}{c}\text { Wyckoff } \\
\text { site }\end{array}$ & $x$ & $y$ & $z$ & $U_{11}$ & $U_{22}$ & $U_{33}$ & $U_{13}$ & $U_{\text {eq }}$ \\
\hline Sc1 & $4 i$ & $0.99626(7)$ & 0 & $0.32367(7)$ & $52(2)$ & $56(2)$ & $47(2)$ & $24(2)$ & $52(1)$ \\
Sc2 & $4 i$ & $0.18356(7)$ & 0 & $0.10753(7)$ & $51(3)$ & $71(3)$ & $57(3)$ & $19(2)$ & $62(1)$ \\
Ru & $4 i$ & $0.26983(4)$ & 0 & $0.62998(4)$ & $38(1)$ & $34(1)$ & $40(1)$ & $16(1)$ & $38(1)$ \\
Si 1 & $4 i$ & $0.36075(9)$ & 0 & $0.4356(1)$ & $53(3)$ & $37(3)$ & $60(4)$ & $31(3)$ & $48(1)$ \\
Si2 & $4 i$ & $0.4873(1)$ & 0 & $0.1215(1)$ & $56(4)$ & $51(3)$ & $44(3)$ & $23(3)$ & $51(2)$ \\
\hline
\end{tabular}

Table 3

Interatomic distances $(\mathrm{pm})$ in the structure of $\mathrm{Sc}_{2} \mathrm{RuSi}_{2}$. Standard deviations are all equal or less than $0.1 \mathrm{pm}$. All distances within the first coordination spheres are listed.

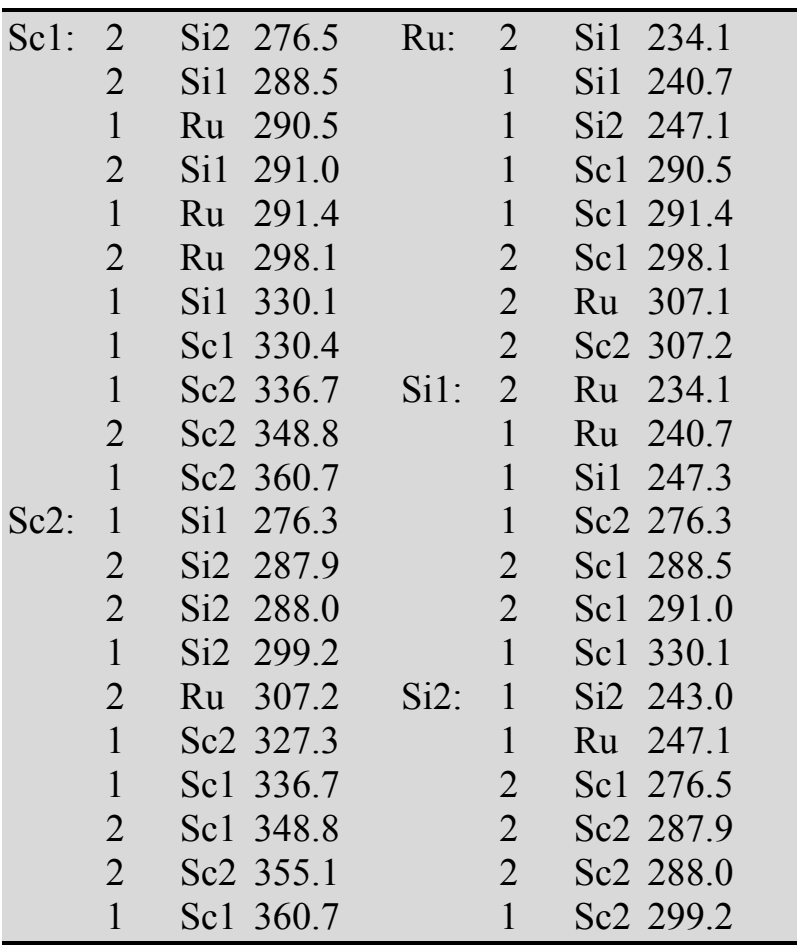


Table 4

Experimental ${ }^{45} \mathrm{Sc}$ NMR parameters of $\mathrm{Sc}_{2} \mathrm{RuSi}_{2}$. Listed are the experimental isotropic resonance shifts $\delta_{\text {iso }}$, nuclear electric quadrupolar coupling constants $\mathrm{C}_{\mathrm{Q}}$, electric field gradient asymmetry parameters $\eta_{\mathrm{Q}}$ and integrated overall intensity.

\begin{tabular}{lccc}
\hline$\delta_{\text {iss }} / \mathrm{ppm}$ & $\mathrm{C}_{\mathrm{Q}} / \mathrm{MHz}$ & $\eta_{\mathrm{Q}}$ & $\%$ \\
\hline $\mathbf{1 1 . 7 ~ T}$ & & & \\
1241 & 11.1 & 0.1 & 48 \\
1113 & 11.4 & 0.3 & 52 \\
$\mathbf{9 . 4 ~ T}$ & & & \\
1242 & 11.3 & 0.1 & 50 \\
1114 & 11.2 & 0.3 & 50 \\
\hline
\end{tabular}




\section{FIGURE CAPTIONS}

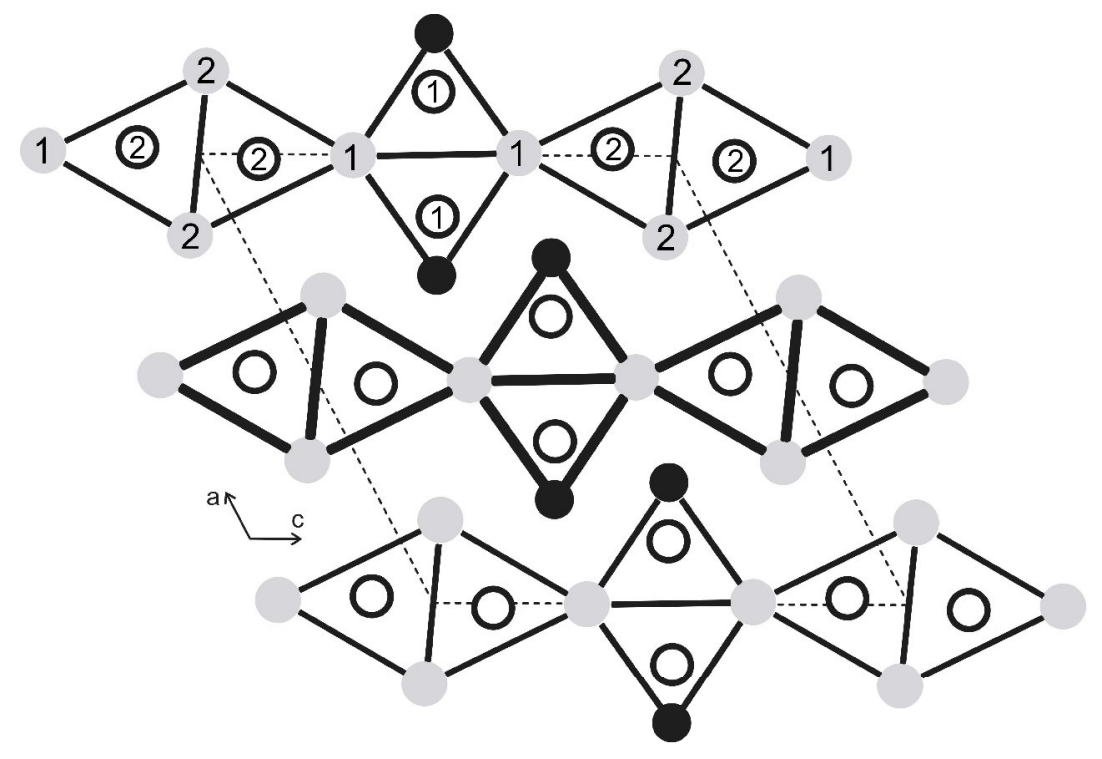

Fig. 1. Projection of the $\mathrm{Sc}_{2} \mathrm{RuSi}_{2}$ structure onto the $x z$ plane. All atoms lie on mirror planes at $y=0$ (thin lines) and $y=1 / 2$ (thick lines). Scandium, ruthenium, and silicon atoms are drawn as light grey, black filled, and open circles, respectively. Atom designations and the trigonal prismatic silicon coordination are emphasized.

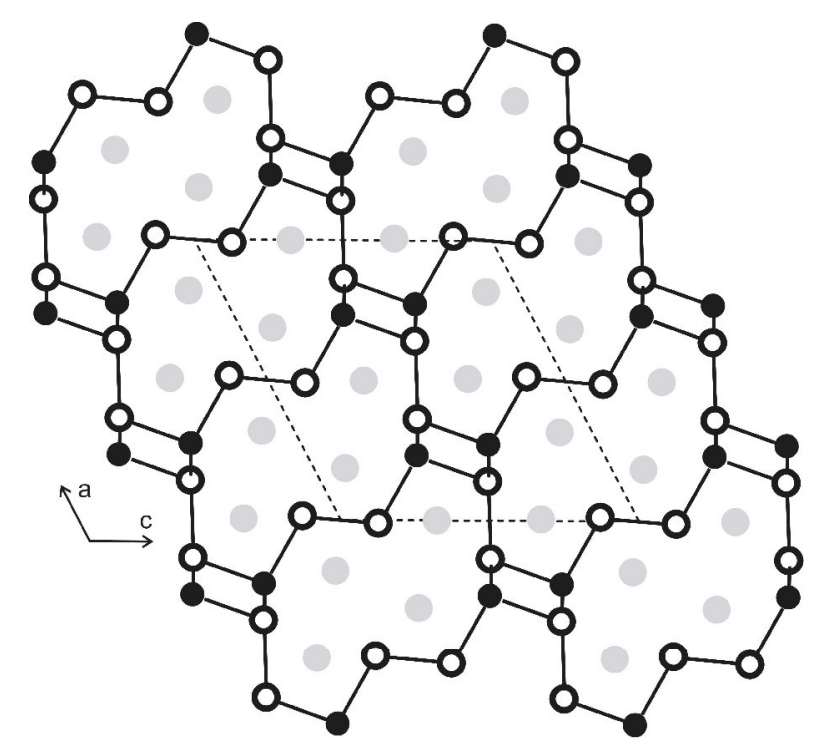

Fig. 2. View of the $\mathrm{Sc}_{2} \mathrm{RuSi}_{2}$ structure along the $y$ axis. Scandium, ruthenium, and silicon atoms are drawn as light grey, black filled, and open circles, respectively. The three-dimensional [ $\left.\mathrm{RuSi}_{2}\right]$ network is emphasized. 


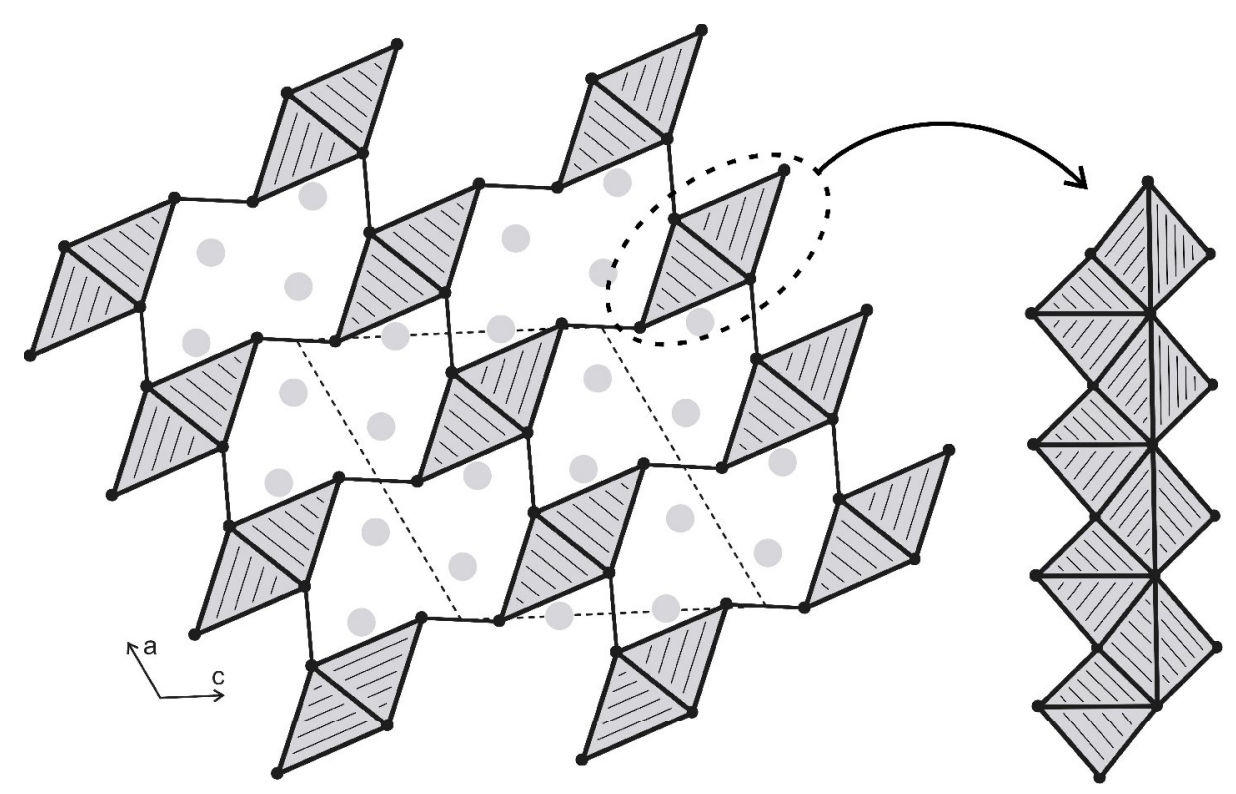

Fig. 3. Connectivity of the $\mathrm{RuSi}_{4 / 2}$ tetrahedra in the structure of $\mathrm{Sc}_{2} \mathrm{RuSi}_{2}$. For details see text.

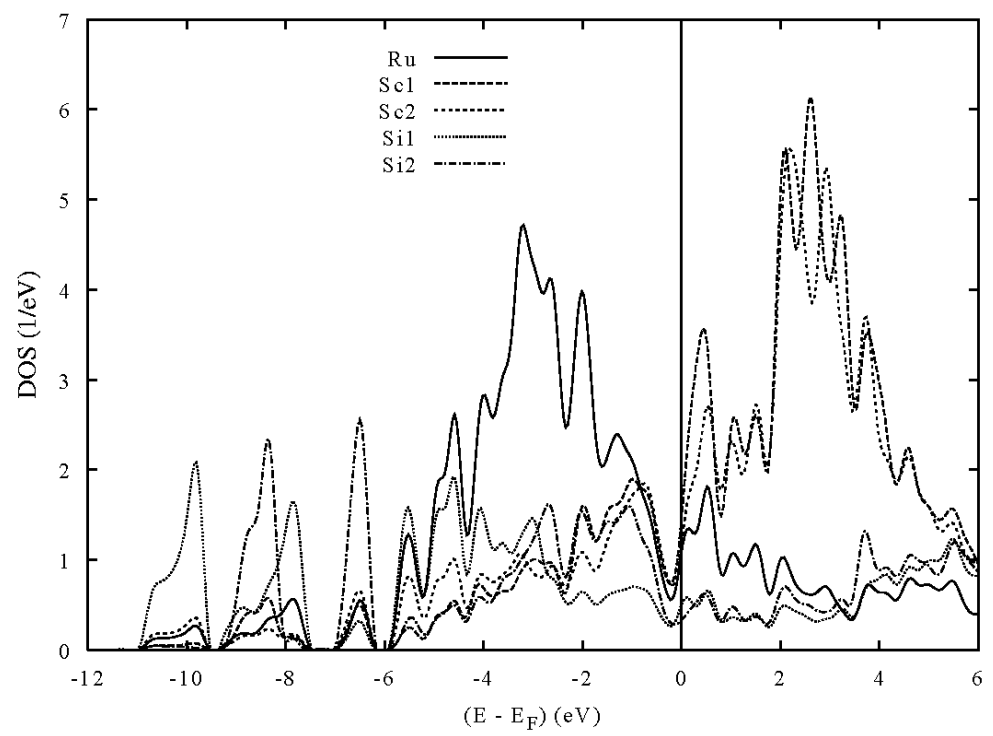

Fig. 4. The site-projected density of states (PDOS) of base-centered monoclinic $\mathrm{Sc}_{2} \mathrm{RuSi}_{2}$ 

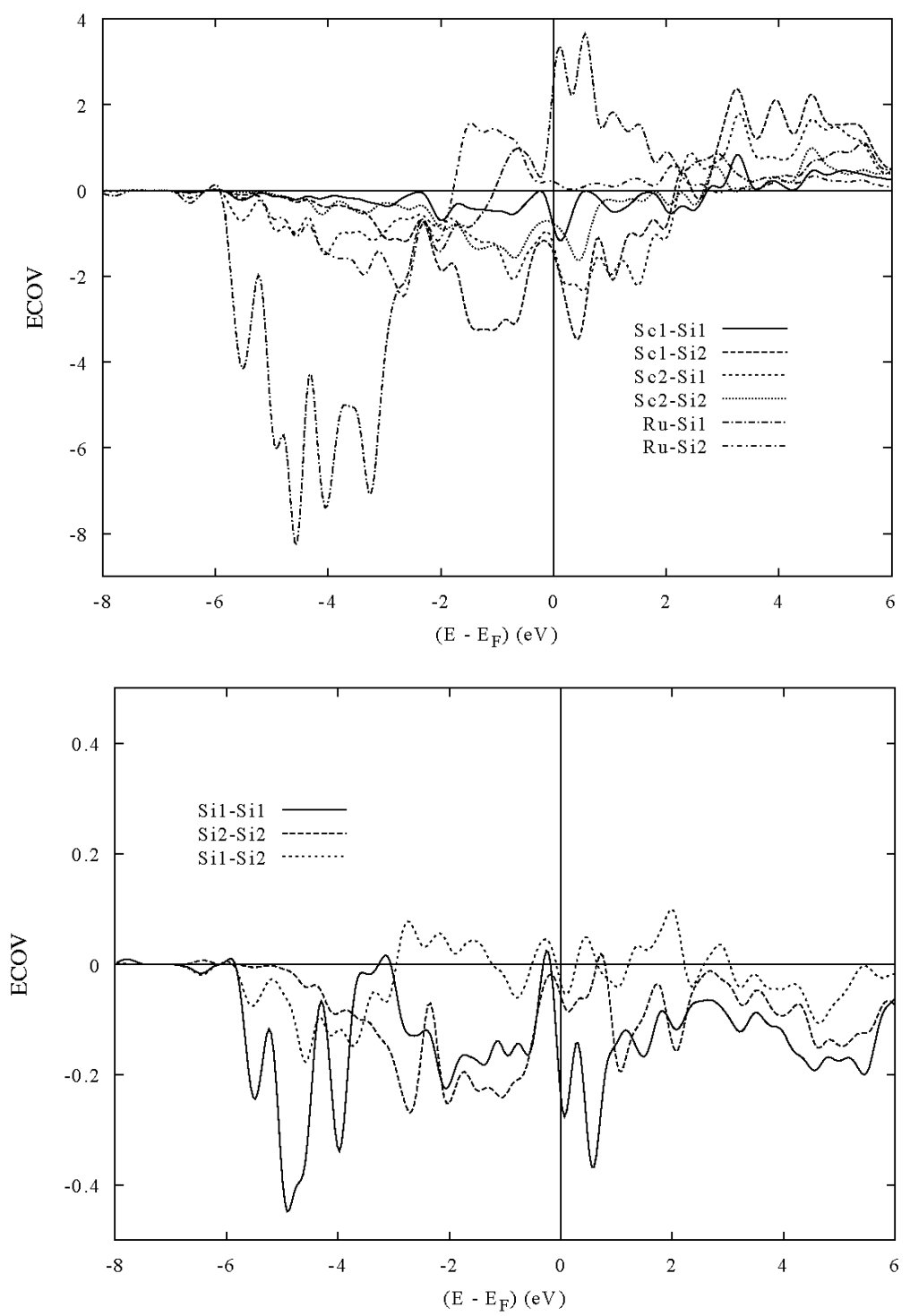

Fig. 5. Chemical bonding of $\mathrm{Sc}_{2} \mathrm{RuSi}_{2}$ from the ECOV criterion. Negative, positive and zero intensity (unit-less) are relevant to bonding, antibonding and non-bonding interactions respectively. Top, the bonding between $\mathrm{Sc}, \mathrm{Ru}$ and $\mathrm{Si}$ and bottom, bonding in the Si substructure. 

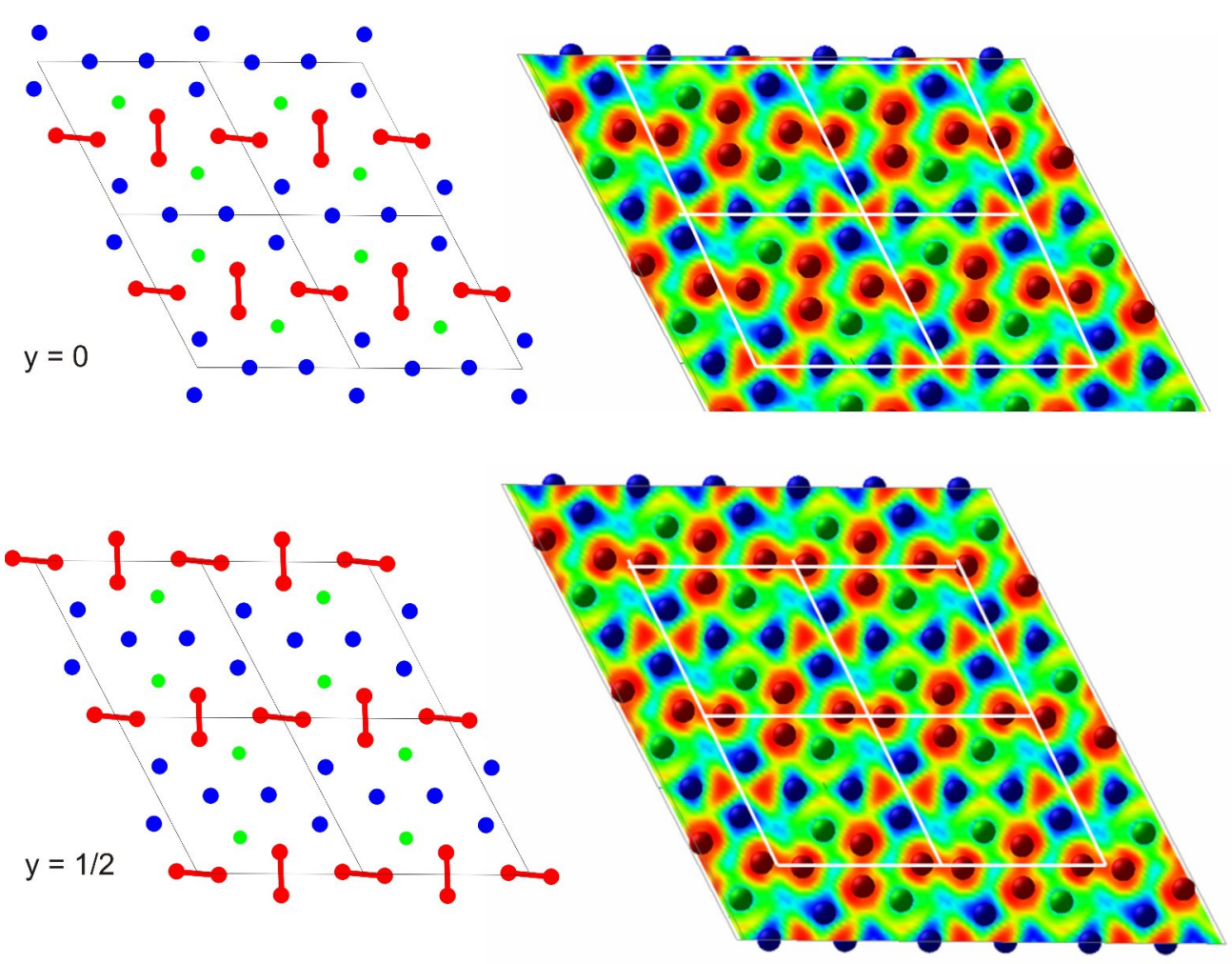

Fig. 6 (color online). Left: The different layers at $y=0$ and $y=1 / 2$ in the Sc2RuSi2 structure. Scandium, ruthenium, and silicon atoms are drawn with blue, green, and red color. Right: ELF contours around Sc (blue spheres), Ru (green spheres) and Si (red spheres). Planes at $y=0$ (top) and $y=1 / 2$ (bottom). 4 adjacent cells are shown. 


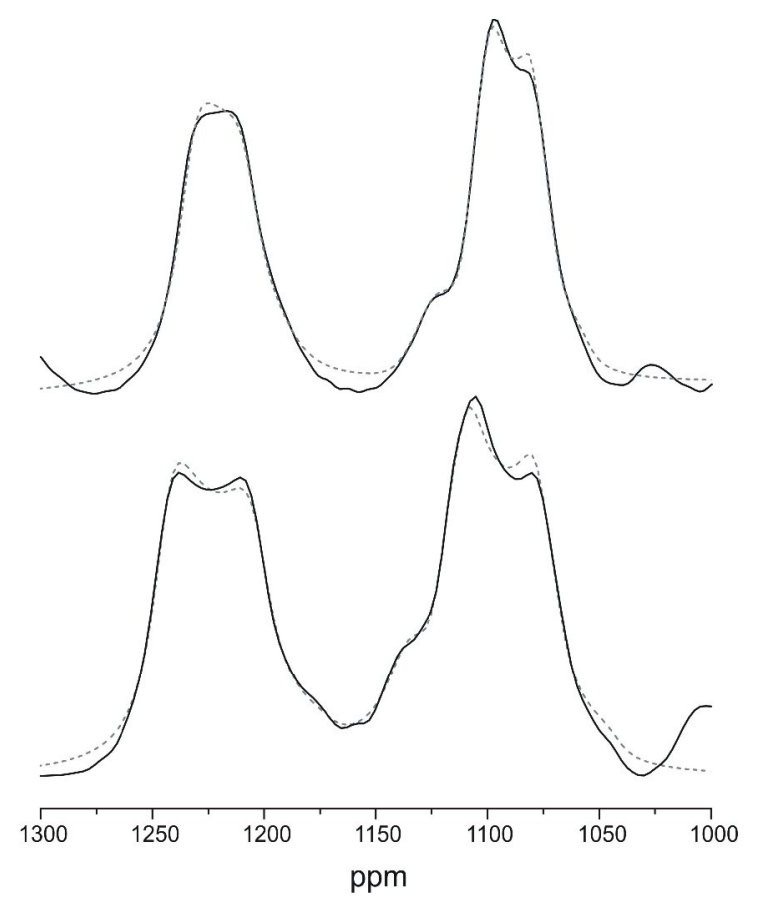

Fig. 7. Solid State ${ }^{45} \mathrm{Sc}$ MAS NMR spectrum of $\mathrm{Sc}_{2} \mathrm{RuSi}_{2}$ at 11.7 (top) and $9.4 \mathrm{~T}$ (bottom) with simulated line shapes (dotted curves), using the DMFIT software. 